\title{
Robotic radical parametrectomy in incidental cervical cancer
}

\author{
Athithan Rattanaburi ${ }^{1}$, Yuyeon Jung ${ }^{2}$, Keun Ho Lee ${ }^{2}$ \\ ${ }^{1}$ Department of Obstetrics and Gynecology, Faculty of Medicine, Prince of Songkla University, Songkhla, Thailand; ${ }^{2}$ Department of Obstetrics and \\ Gynecology, Seoul St. Mary's Hospital, The Catholic University of Korea, Seoul, Korea
}

Key Words: Incidental cervical cancer; Parameterectomy; Manupulator

Incidental cervical cancer can be found after hysterectomy [1]. After final pathology, radiotherapy and radical surgery are the standard treatments of incidental cervical cancer. But radical parametrectomy would be provided if the cancer were found by the frozen section during the operation [2]. A 36-year-old woman with CIN3 and adenocarcinoma in situ on conization had a total hysterectomy. On frozen section pathology, invasive cervical cancer was found. Radical parametrectomy was performed without uterine manupulator. After the closure of vaginal cuff, retroperitoneal space was open to dissect the pelvic lymph nodes. Uterine artery was identified and coagulated at the level of bifurcation. Ureter was separated from the uterine artery and ureter tunnel was developed. Anterior vesicovaginal space and posterior rectovaginal space were dissected and colpotomy was made. After closure of vagina, ovarian transposition to both paracolic gutter was done. Total operational time was 255 minutes and console time was 170 minutes. There were no intra- and post-operative complications.

\section{Video related to this article}

The video related to this article can be found online at 10.36637/grs.2021.00045.

\section{Conflict of interest}

No potential conflict of interest relevant to this article was reported.

\section{References}

1. Ha HI, Chang HK, Park SJ, Lim J, Won YJ, Lim MC. The incidence and survival of cervical, ovarian, and endometrial cancer in Korea, 1999-2017: Korea Central Cancer Registry. Obstet Gynecol Sci 2021;64:444-53

2. Ng JS, Leitao MM, Lim PC, Kim TJ, Kim SW. Asian Society for Gynecologic Robotic Surgery consensus guidelines on robotic surgery in gynecological cancer. Gyne Robot Surg 2020;1:2-13.

- Received: September 19, 2021 • Accepted: September 20, 2021

- Correspondening author: Keun Ho Lee

Department of Obstetrics and Gynecology, Seoul St. Mary's Hospital, The Catholic University of Korea, 222 Banpo-daero, Seocho-gu, Seoul 06591, Korea E-mail:hohoho@catholic.ac.kr

This is an Open Access article distributed under the terms of the Creative Commons Attribution Non-Commercial License (http://creativecommons.org/ licenses/by-nc/4.0) which permits unrestricted non-commercial use, distribution, and reproduction in any medium, provided the original work is properly cited. 
GRS

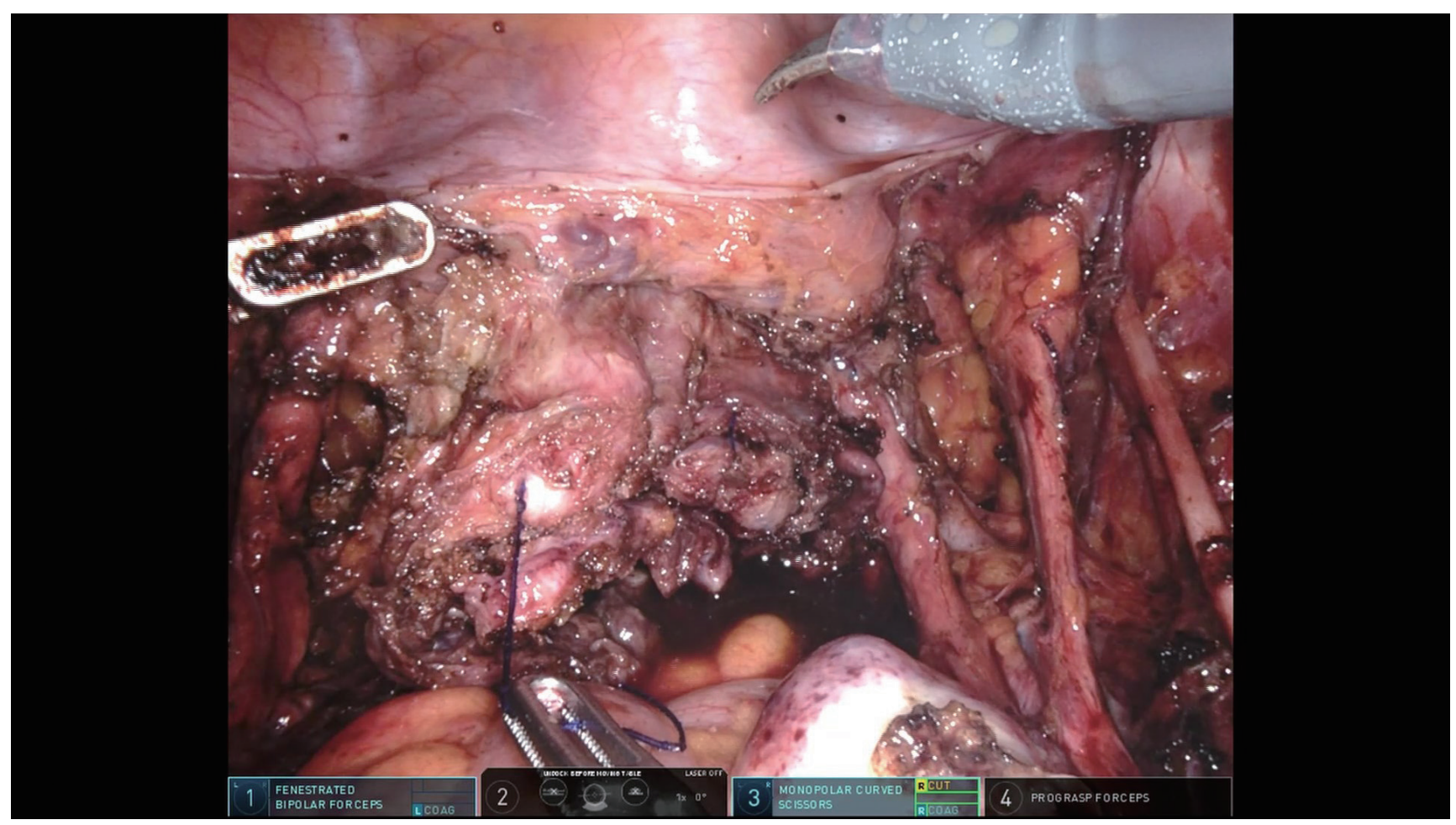

Video 1. 